Artículo

\title{
Efecto de Methylobacterium extorquens en el desarrollo del tomate en presencia o ausencia de Fusarium oxysporum
}

\author{
Melissa Medina Rios ${ }^{1}$ \\ Luis Fernando Ceja Torres ${ }^{1 \S}$ \\ Sigifredo López Díaz ${ }^{1}$ \\ José Venegas González ${ }^{1}$ \\ Carla Vanessa Sánchez Hernández ${ }^{2}$ \\ ${ }^{1}$ Instituto Politécnico Nacional-CIIDIR-Unidad Michoacán. Justo Sierra \# 28, Col. Centro, Jiquilpan de \\ Juárez, Michoacán, México. CP. 59510. ${ }^{2}$ Departamento de Producción Agrícola-CUCBA-Universidad de \\ Guadalajara. Carretera Guadalajara-Nogales km 15.5, predio las Agujas, Nextipac, Zapopan, Jalisco, \\ México. \\ ${ }^{\S}$ Autor para correspondencia: Ifceja@ipn.mx.
}

\section{Resumen}

La marchitez del tomate (Fusarium oxysporum) promueve el uso desmedido de fungicidas sintéticos, que no son económica ni ambientalmente viables. Este trabajo plantea el uso de Methylobacterium extorquens para determinar su efecto sobre el desarrollo vegetal y la vía de señalización, para la defensa de plantas de jitomate, contra fitopatógenos. A partir, de semillas de tomate var. SUN 7705 embebidas y plantas asperjadas con la bacteria a una concentración de $10^{9}$ UFC $\mathrm{mL}^{-1}$, se retó a la planta con el hongo en dos ensayos. Se midieron variables de longitud de raíz en plántulas, altura de la planta, amplitud foliar, rendimiento, peso seco total de la planta y peso seco de la raíz. Se utilizó un diseño completamente al azar con seis tratamientos y cuatro repeticiones, dos plantas formaron la unidad experimental. Asimismo, se realizó un ensayo sobre la expresión de genes de defensa, en plántulas de tomate de la misma variedad. Se encontraron diferencias estadísticas significativas $(p \leq 0.05)$ entre tratamientos embebidos y asperjados con M. extorquens y los tratamientos inoculados con F. oxysporum y los controles, reflejándose en la longitud de raíz de plántulas, altura de la planta, amplitud foliar, peso seco de la planta y de la raíz, así como en el rendimiento. Sin embargo, los genes que codifican para el grupo enzimático fenilalanina amonio liasa (PAL), proteínas (PR-6), superóxido dismutasa (SOD) y lipoxigenasa (LOX), no se expresaron significativamente en las plántulas tratadas con M. extorquens.

Palabras clave: Fusarium, Methylobacterium extorquens, Solanum lycopersicum, Oxysporum, control biológico.

Recibido: julio de 2019

Aceptado: septiembre de 2019 


\section{Introducción}

En México, el jitomate es una de las principales hortalizas producidas en áreas de riego y temporal, por el número considerable de agricultores dedicados a esta actividad, sus precios que pueden llegar a ser atractivos, su aceptación por los consumidores y por la captación de divisas para este país (Vargas y Martínez, 2004). La producción de tomate en invernadero también ha mostrado un incremento considerable; sin embargo, la marchitez originada particularmente por Fusarium oxysporum f. sp. lycopersici, ha ocasionado pérdidas importantes (Carrillo-Fasio et al., 2003; Ascencio-Álvarez et al., 2008).

En la búsqueda de alternativas respetuosas al medio ambiente para el control del fitopatógenos, se han encontrado diferentes bacterias benéficas para las plantas y antagónicas a hongos fitopatógenos, dentro de las cuales se encuentran los miembros el género Methylobacterium mismas que por su carácter ubicuo, colonizan diferentes hábitats incluyendo suelo, agua, superficies de las hojas, nódulos, semillas y aire (Corpe, 1985; Corpe y Rheem, 1989; NóbregaDourado et al., 2015), así como en tejidos internos del hospedante; es decir, pueden actuar como endosimbiontes (Sy et al., 2005) e inhibir y antagonizar hongos entre ellos algunos del género Fusarium (Poorniammal, 2009; Nóbrega-Dourado et al., 2015).

Algunas bacterias que contribuyen a la fijación de nitrógeno, al incremento de la toma de nutrientes, a la síntesis y fijación de fitohormonas pueden estar vinculadas con el desarrollo vegetal y se les considera en el grupo de bacterias promotoras de crecimiento BPCV (Loredo-Osti, 2004). En la última década, ha llamado la atención de algunos investigadores las bacterias metilotroficas aeróbicas por sus propiedades fitosimbióticas, relacionadas con la producción de auxinas (ácido indol-3-acético, indol-3-pirúvico y ácido indol-3-butírico) y citocininas (zeatina, trans zeatina y ribósido trans-zeatina), responsables del crecimiento de las plantas; a través, de la división celular y el aumento en la elongación de las células, tanto de las raíces como de la parte aérea; asimismo, por su capacidad para inducir efectos de respuestas defensivas en plantas contra fitopatógenos.

También se ha demostrado que el uso de Methylobacterium spp., ha ejercido un efecto positivo en el desarrollo de arroz, caña de azúcar y maní; así como en la elongación de la raíz en plántulas de chile y jitomate (Madhaiyan et al., 2004, 2005, 2006; Ryu et al., 2006). Por lo anterior, el objetivo de este trabajo fue determinar el efecto de Methylobacterium extorquens sobre el desarrollo vegetal y la vía de señalización, para la defensa de plantas de jitomate, contra fitopatógenos.

\section{Materiales y métodos}

La investigación se desarrolló en el Centro Interdisciplinario de Investigación para el Desarrollo Integral Regional (CIIDIR-IPN), ubicado en la ciudad de Jiquilpan, Michoacán, México, entre las coordenadas $19^{\circ} 59^{\prime}$ de latitud norte y $102^{\circ} 43^{\prime}$ de longitud oeste, a una altura de $1550 \mathrm{msnm}$.

\section{Aislamiento e identificación de Methylobacterium extorquens}

A partir, de hojas de jitomate se realizó el aislamiento de Methylobacterium sp. en un medio selectivo sólido de amonio y sales minerales (AMS) por sus siglas en inglés, el cual contenía por litro: $0.8 \mathrm{~g}$ de agar, $0.5 \mathrm{~g}$ de cloruro de amonio, $\left(\mathrm{NH}_{4} \mathrm{Cl}\right), 0.54 \mathrm{~g}$ de fosfato diácido de potasio, 
$\left(\mathrm{KH}_{2} \mathrm{PO}_{4}\right), 0.7 \mathrm{~g}$ de fosfato dipotásico, $\left(\mathrm{K}_{2} \mathrm{HPO}_{4}\right), 1 \mathrm{~g}$ de sulfato de magnesio heptahidratado, $\left(\mathrm{MgSO}_{4} 7 \mathrm{H}_{2} \mathrm{O}\right), 0.2 \mathrm{~g}$ de cloruro de calcio dihidratado, $\left(\mathrm{CaCl}_{2} .2 \mathrm{H}_{2} \mathrm{O}\right), 4 \mathrm{mg}$ de sulfato de hierro heptahidratado $\left(\mathrm{FeSO}_{4} 7 \mathrm{H}_{2} \mathrm{O}\right), 0.1 \mathrm{mg}$ de sulfato de zinc heptahidratado $\left(\mathrm{ZnSO}_{4} 7 \mathrm{H}_{2} \mathrm{O}\right), 0.03 \mathrm{mg}$ de cloruro de manganeso tetrahidratado $\left(\mathrm{MnCl}_{2} 4 \mathrm{H}_{2} \mathrm{O}\right), 0.3 \mathrm{mg}$ de ácido bórico, $\left(\mathrm{H}_{3} \mathrm{BO}_{3}\right), 0.2 \mathrm{mg}$ de cloruro de cobalto hexahidratado $\left(\mathrm{CoCl}_{2} 6 \mathrm{H}_{2} \mathrm{O}\right), 0.01 \mathrm{mg}$ de cloruro de cobre dihidratado $\left(\mathrm{CuCl}_{2}\right.$ $\left.2 \mathrm{H}_{2} \mathrm{O}\right), 0.02 \mathrm{mg}$ de cloruro de níquel hexahidratado $\left(\mathrm{NiCl}_{2} 6 \mathrm{H}_{2} \mathrm{O}\right), 0.06 \mathrm{mg}$ de molibdato de sodio dihidratado $\left(\mathrm{Na}_{2} \mathrm{Mo} \mathrm{O}_{4} 2 \mathrm{H}_{2} \mathrm{O}\right)$.

Se ajustó el pH a $6.8 \pm 0.2$ a $25^{\circ} \mathrm{C}$ y se adicionaron $0.5 \mathrm{~mL}$ de metanol con $0.05 \mathrm{~g} \mathrm{~L}^{-1}$ de PCNB. Las placas Petri se colocaron en la incubadora a $26^{\circ} \mathrm{C}$ por un lapso de $72 \mathrm{~h}$ para el desarrollo de la bacteria (Ryu et al., 2006). El inóculo se preparó desarrollando las bacterias en medio de cultivo líquido en su fase media exponencial con una densidad óptica de $600 \mathrm{~nm}\left(\mathrm{DO}_{600}=1.2\right)$, seguida por una centrifugación durante $15 \mathrm{~min}$ a $3000 \mathrm{x}$ g, lavando y resuspendiendo en una solución de sulfato de magnesio $\left(\mathrm{MgSO}_{4}\right) 30 \mathrm{mM}$ hasta obtener una densidad celular de $10^{9} \mathrm{UFC}$ por $\mathrm{mL}\left(\mathrm{OD}_{600}=\right.$ 1.2). Seguido de una agitación orbital durante $24{ }^{\circ} \mathrm{C}$ por $48 \mathrm{~h}$.

El gen 16S se amplifico por PCR a partir del DNA extraído, utilizando los primeros de acuerdo con la metodología descrita por Weisburg et al. (1991). El proceso de secuenciación se realizó en el Laboratorio de Servicios Genómicos del Laboratorio Nacional de Genómica para la Biodiversidad (LANGEBIO). La secuencia de nucleótidos obtenida se comparó con secuencias de genes 16S rDNA en las bases de datos Silva (http://www.arb-silva.de) para identificar la especie bacteriana a la cual pertenecía la secuencia, en este caso M. extorquens.

\section{Aislamiento e identificación de Fusarium oxysporum}

El hongo se aisló de la raíz de la planta de jitomate enferma con síntomas de marchitez. Raíces necróticas fueron cortadas en secciones de 1 a $2 \mathrm{~cm}$ de longitud y colocadas en una solución con hipoclorito de sodio al 3\% durante 2 min, se enjuagaron en 3 ocasiones con agua estéril y se secaron en sanitas asépticas, en seguida se colocaron en medio de cultivo papa dextrosa agar (PDA) a temperatura de $25^{\circ} \mathrm{C} \pm 1{ }^{\circ} \mathrm{C}$ por un periodo de 5 días para el desarrollo del hongo.

El cual fue purificado por la técnica de punta de hifa e identificado en base a sus características morfológicas, citadas por Nelson et al. (1983). La patogenicidad de la cepa fue comprobada de acuerdo a los postulados de Koch. Para lo cual se inocularon cuatro plantas sanas en la base del tallo y raíces de jitomate con pequeñas heridas, con una concentración de 1 x $10^{6} \mathrm{UFC} \mathrm{mL}^{-1}$; a partir, de cultivos puros del hongo. A las cuatro plantas testigo también se les hicieron heridas, pero sin inóculo.

\section{Efecto de M. extorquens en la germinación de semillas y longitud de raíz}

Semillas de jitomate variedad SUN 7705 fueron aseptizadas en etanol 95\%, además se trataron con hipoclorito de sodio al $50 \mathrm{v} / \mathrm{v}$ y $10 \mu \mathrm{l}$ de tween $20 \%$, en ambos casos fueron enjuagadas en repetidas ocasiones con agua estéril. 20 semillas se colocaron en un matraz que contenía $100 \mathrm{~mL}$ de una solución de MgSO4 al $0.03 \mathrm{M}$, a la cual se le adicionó el inóculo de M. extorquens, a partir de cultivo puro con un asa bacteriológica, hasta obtener una concentración de $10^{9} \mathrm{UFC} \mathrm{mL}^{-1}$ (tratamiento M). 20 semillas consideradas como testigo (C), fueron igualmente aseptizadas y embebidas en la misma solución, pero sin la bacteria. 
Las 40 semillas de ambos tratamientos fueron colocadas individualmente en cavidades de una charola germinadora con peat moss y vermiculita (2:1). A los siete días después de la siembra (dds) se determinó el porcentaje de germinación y a los 21 dds se midió la longitud de la raíz. El ensayo se repitió en dos ocasiones y se hizo una prueba de $t$ de Student para determinar diferencias estadísticas.

\section{Efecto de M. extorquens en planta de jitomate}

El cultivo de jitomate variedad SUN 7705, se llevó a cabo en macetas de 5 L de capacidad con sustrato a base de peat moss y vermiculita (2:1) esterilizados mediante solarización por 30 días. A partir de semillas embebidas con $\mathrm{MgSO}_{4}$ al $0.03 \mathrm{M}$ durante $12 \mathrm{~h}$ en agitación, con y sin inóculo de M. extorquens se conformaron los tratamientos siguientes: 1) plantas a partir de semillas embebidas sin bacteria (C), testigo 1,2 ) semillas embebidas y plantas asperjadas con $\mathrm{MgSO}_{4}$ al $0.03 \mathrm{M}$ sin bacteria (CA), testigo 2, 3) plantas a partir de semillas embebidas sin bacteria e inoculadas con $\mathrm{F}$. oxysporum (F); 4) plantas. A partir de semillas embebidas con M. extorquens (M); 5) plantas a partir de semillas embebidas con bacteria e inoculadas con el hongo (MF); y 6) semillas embebidas y plantas asperjadas con la bacteria e inoculadas con el hongo (MFA).

Las inoculaciones en las plantas se hicieron a 41 días después de la emergencia; en el caso del hongo se realizaron al cuello de la planta de jitomate con $12 \mathrm{~mL}$ de una suspensión de F. oxysporum a una concentración de $10^{6} \mathrm{UFC} \mathrm{mL}^{-1}$, la suspensión bacteriana fue asperjada en el área foliar, con $50 \mathrm{ml}$ de solución de $\mathrm{MgSO} 4$ al $0.03 \mathrm{M}$ a concentración de $10^{9} \mathrm{UFC} \mathrm{mL}^{-1}$ durante 3 días consecutivos.

\section{Variables evaluadas}

Variables de altura y amplitud de la planta se realizaron a los 30, 60 y 90 días después de la siembra (dds), la producción de fruto se cuantificó durante el ciclo de cultivo y al final de éste se registró el peso seco total de la planta y de la raíz, en una balanza electrónica Marca Ohaus CS 2000, previo secado en un horno marca FELISA a $70{ }^{\circ} \mathrm{C}$ hasta obtener peso constante. Se utilizó un diseño completamente al azar con seis tratamientos y cuatro repeticiones, la unidad experimental se constituyó por dos plantas. El análisis de varianza (Anova) y la comparación de promedios por la prueba de Tukey $(p \leq 0.05)$ se hizo mediante el paquete estadístico SAS (Statistical Analisis System) para Windows v. 9.

\section{Ensayos de expresión de genes}

Semillas de jitomate variedad SUN 7705 fueron colocadas en solución de $\mathrm{MgSO}_{4}$ al $0.03 \mathrm{M}$ inoculada mediante la técnica del asa, con un cultivo puro de $M$. extorquens a una concentración de $10^{9} \mathrm{UFC} \mathrm{mL}^{-1}$ durante $12 \mathrm{~h}$ en agitación (tratamiento M); otras semillas se pusieron en la misma solución y bajo las mismas condiciones, sin inocular la bacteria (tratamiento C). Semillas de ambos tratamientos se sembraron en charolas germinadoras con sustrato de peat moss y vermiculita 2:1 estéril; así permanecieron en una cámara de crecimiento a $28^{\circ} \mathrm{C}$, con $18 \mathrm{~h} \mathrm{luz} \mathrm{y} 8 \mathrm{~h}$ de obscuridad.

A los 22 de crecimiento de las plántulas, se colectaron hojas de cada tratamiento, se congelaron y molieron con nitrógeno líquido. Para determinar la vía de señalización que Methylobacterium pudiera inducir, para la defensa de la planta de jitomate contra fitopatógenos, se realizó la extracción de RNA por medio del Kit de extracción de columnas y se hizo una RT-PCR utilizando 
dos sondas: la P6 que codifica para el gen marcador de la ruta del ácido salicílico y la Pin2 relacionado con la ruta del ácido jasmónico, se usó como control el 18S ribosomal. Protocolos estándar acordes a la taq utilizada (invitrogen) fueron considerados; para el RT se utilizó la comercial de fermentas, donde los productos esperados son del tamaño P6 $=450 \mathrm{pb}, \mathrm{Pin} 2=302 \mathrm{y}$ $18 \mathrm{~S}=506 \mathrm{pb}$.

Se corrieron 28 ciclos para los marcadores de ambas vías de señalización (P6 y Pin2), mientras que para $18 \mathrm{~S}$ se utilizaron solo 22 ciclos. Por otra parte, las plántulas del tratamiento $\mathrm{M}$ se asperjaron con $20 \mathrm{ml}$ de la suspensión bacteriana a una concentración de $10^{9} \mathrm{UFC} \mathrm{mL}^{-1}$ y se colectaron a las 24 y 72 h para hacer el ensayo por duplicado (M1 y M2), las plántulas del tratamiento C se asperjaron con la misma solución sin la bacteria y se colectaron al tiempo 0 (C1 y C2). Obtenidas las muestras, se extrajo el RNA mediante la técnica Plant RNA Reagent y el cDNA promega, se realizó un primer PCR donde el control fue el 18S ribosomal y un segundo con las sondas Pal y P6 para la vía del ácido salicílico, con un tamaño esperado de 687 pb y 450 pb respectivamente.

También se utilizaron las sondas SOD y LOX para la vía del ácido jasmónico. En ambos casos se utilizó el protocolo estándar acorde a la taq utilizada (invitrogen). Las condiciones del RT-PCR fueron iguales a las del primer ensayo a diferencia del número de ciclos los cuales fueron para $\mathrm{PAL}=25$ ciclos, $\mathrm{P} 6=25, \mathrm{SOD}=22$ y $\mathrm{LOX}=33$ ciclos. Para determinar la diferencia estadística en la intensidad de expresión de genes, se utilizó el programa Imagen 1.44 y el paquete estadístico Statgraphics 4.0 con un Anova al 95\% de confiabilidad. La intensidad en la que se expresaron los genes de resistencia en la planta de jitomate, fueron graficados para cada uno de los tratamientos en los que se buscaba respuesta.

\section{Resultados y discusión}

\section{Efecto de M. extorquens en la germinación de semillas y longitud de raíz}

El porcentaje de germinación promedio en ambos ensayos fue mayor en las semillas de jitomate inoculadas con M. extorquens (97\%) comparado con las semillas embebidas sin la bacteria (92\%) (Cuadro 1). Respuestas similares con la aplicación de esta bacteria, se han reportado en la germinación de trigo, cebada y maíz (Abanda-Nkpwatt, 2006).

Esto puede estar relacionado con el incremento en la producción de la vitamina B12 y de hormonas como las citocininas (zeatina, trans-zeatina y ribósido trans-zeatina) y auxinas (ácido indol-3acético, indol-3-pirúvico y ácido indol-3-butírico) las cuales estimularon la germinación de semillas y el crecimiento de plantas de arroz (Maghaiyan et al., 2004).

La longitud de la raíz en plántulas de jitomate de tres semanas de edad fue mayor estadísticamente $(p \leq 0.05)$ en el tratamiento con Methylobacterium comparado con el testigo (Cuadro 1). Estos resultados concuerdan con los reportados en jitomate y pimiento rojo (Ryu et al., 2006), en arroz (Maghaiyan et al., 2004), chile y jitomate, donde además se comprobó un incremento en la producción de auxinas (ácido indol-3-acético) y citocininas en plantas tratadas con dicha bacteria (Ryu et al., 2006), lo cual puede explicar el incremento en la elongación de la raíz de jitomate, aún cuando estas fitohormonas no fueron cuantificadas en este estudio. 
Cuadro 1. Longitud de raíz de plántulas de jitomate, con y sin M. extorquens.

\begin{tabular}{cccc}
\hline \multirow{2}{*}{ Tratamientos } & \multirow{2}{*}{ Germinación de semillas } & \multicolumn{2}{c}{ Longitud de raíz $(\mathrm{mm})$} \\
\cline { 3 - 4 } & & Ensayo 1 & Ensayo 2 \\
\hline $\mathrm{C}^{\star}$ & $92 \%$ & $39.5 \mathrm{~b}^{*}$ & $50 \mathrm{~b}$ \\
$\mathrm{M}$ & $97 \%$ & $75.9 \mathrm{a}$ & $90.8 \mathrm{a}$ \\
\hline
\end{tabular}

$*$ = valores con diferente letra dentro de cada columna, son estadísticamente diferentes, Tukey $(p \leq 0.05)$. ${ }^{\star} \mathrm{C}=$ semillas embebidas en $\mathrm{MgSO}_{4}$ al $0.03 \mathrm{M}$ (testigo); $\mathrm{M}=$ semillas embebidas en $\mathrm{MgSO}_{4}$ al $0.03 \mathrm{M}$ inoculadas con Methylobacterium extorquens.

\section{Efecto de M. extorquens en planta de jitomate}

Resultados con respecto a la altura y amplitud de las plantas de jitomate, fueron similares en ambos ciclos de cultivo, donde el tratamiento M (semillas embebidas con $M$. extorquens), ejerció diferencias estadísticas en la altura de las plantas de $27.2 \mathrm{~cm}$ a los 90 dds en el primer ensayo (Cuadro 2) y de $16.7 \mathrm{~cm}$ con respecto al testigo 1 (C) en el segundo ensayo (Cuadro 3).

Cuadro 2. Altura y amplitud de plantas de jitomate en invernadero, con y sin $M$. extorquens (primer ensayo).

\begin{tabular}{cccccccc}
\hline \multirow{2}{*}{ Tratamientos } & \multicolumn{3}{c}{ Altura de plantas $(\mathrm{cm})$} & & \multicolumn{3}{c}{ Diámetro de follaje $(\mathrm{cm})$} \\
\cline { 2 - 3 } \cline { 7 - 8 } & $30 \mathrm{dds}$ & $60 \mathrm{dds}$ & $90 \mathrm{dds}$ & & $30 \mathrm{dds}$ & $60 \mathrm{dds}$ & $90 \mathrm{dds}$ \\
\hline $\mathrm{C}^{\star}$ & $16.5 \mathrm{c}^{*}$ & $78.5 \mathrm{bcd}$ & $87 \mathrm{bc}$ & & $25.5 \mathrm{c}$ & $42.7 \mathrm{~b}$ & $45 \mathrm{c}$ \\
CA & $15.7 \mathrm{c}$ & $75.7 \mathrm{~cd}$ & $84 \mathrm{bc}$ & & $25.2 \mathrm{c}$ & $41.5 \mathrm{~b}$ & $44 \mathrm{c}$ \\
$\mathrm{F}$ & $14 \mathrm{c}$ & $67.2 \mathrm{~d}$ & $77.7 \mathrm{c}$ & & $21.7 \mathrm{~d}$ & $36.7 \mathrm{c}$ & $38.7 \mathrm{~d}$ \\
$\mathrm{M}$ & $24.2 \mathrm{a}$ & $93 \mathrm{a}$ & $114.2 \mathrm{a}$ & & $37.2 \mathrm{a}$ & $56 \mathrm{a}$ & $59.5 \mathrm{a}$ \\
MF & $19.7 \mathrm{~b}$ & $81.7 \mathrm{abc}$ & $98.5 \mathrm{ab}$ & & $31.7 \mathrm{~b}$ & $52.2 \mathrm{a}$ & $55.5 \mathrm{~b}$ \\
MFA & $19.7 \mathrm{~b}$ & $89.2 \mathrm{ab}$ & $107.7 \mathrm{a}$ & & $33.2 \mathrm{~b}$ & $53.5 \mathrm{a}$ & $56.7 \mathrm{ab}$ \\
\hline
\end{tabular}

* = valores con diferente letra dentro de cada columna, son estadísticamente diferentes, Tukey $(p \leq 0.05)$; $\mathrm{C}^{*}=$ semillas embebidas en $\mathrm{MgSO}_{4}$ al $0.03 \mathrm{M}$ (testigo 1); $\mathrm{CA}=$ semillas embebidas y plantas asperjadas con $\mathrm{MgSO}_{4}$ al $0.03 \mathrm{M}$ (testigo 2); $\mathrm{F}=$ plantas inoculadas con $\mathrm{F}$. oxysporum; $\mathrm{M}=$ semillas embebidas con Methylobacterium; $\mathrm{MF}=$ plantas a partir de semillas embebidas con la bacteria e inoculadas con el hongo. MFA= semillas embebidas y plantas asperjadas con la bacteria e inoculadas con el hongo.

Cuadro 3. Altura y amplitud de plantas de jitomate en invernadero, con y sin M. extorquens (segundo ensayo).

\begin{tabular}{lccccccc}
\hline \multirow{2}{*}{ Tratamientos } & \multicolumn{3}{c}{ Altura de plantas $(\mathrm{cm})$} & & \multicolumn{3}{c}{ Diámetro de follaje $(\mathrm{cm})$} \\
\cline { 2 - 5 } \cline { 7 - 8 } & $30 \mathrm{dds}$ & $60 \mathrm{dds}$ & $90 \mathrm{dds}$ & & $30 \mathrm{dds}$ & $60 \mathrm{dds}$ & $90 \mathrm{dds}$ \\
\hline $\mathrm{C}^{\star}$ & $16.7 \mathrm{~cd}^{*}$ & $61.5 \mathrm{bcd}$ & $93.5 \mathrm{c}$ & & $26.7 \mathrm{c}$ & $43.5 \mathrm{~cd}$ & $45.2 \mathrm{c}$ \\
$\mathrm{CA}$ & $16.7 \mathrm{~cd}$ & $59.5 \mathrm{~cd}$ & $93 \mathrm{c}$ & & $25.2 \mathrm{~cd}$ & $42 \mathrm{~cd}$ & $44.5 \mathrm{c}$ \\
$\mathrm{F}$ & $14.5 \mathrm{~d}$ & $56.5 \mathrm{~d}$ & $76 \mathrm{~d}$ & & $23.2 \mathrm{~d}$ & $40 \mathrm{~d}$ & $39.7 \mathrm{~d}$ \\
$\mathrm{M}$ & $22.2 \mathrm{a}$ & $76.2 \mathrm{a}$ & $110.2 \mathrm{a}$ & & $36.7 \mathrm{a}$ & $53.5 \mathrm{a}$ & $57.5 \mathrm{a}$ \\
$\mathrm{MF}$ & $18.7 \mathrm{bc}$ & $67.7 \mathrm{abc}$ & $97.5 \mathrm{bc}$ & & $28.5 \mathrm{bc}$ & $46.2 \mathrm{bc}$ & $51.5 \mathrm{~b}$ \\
MFA & $20 \mathrm{ab}$ & $69 \mathrm{ab}$ & $102.2 \mathrm{ab}$ & & $30.2 \mathrm{~b}$ & $49.2 \mathrm{ab}$ & $53.5 \mathrm{ab}$ \\
\hline
\end{tabular}

${ }^{*}=$ valores con diferente letra dentro de cada columna, son estadísticamente diferentes, Tukey $(p \leq 0.05)$; $\mathrm{C}^{*}=$ semillas embebidas en $\mathrm{MgSO}_{4}$ al $0.03 \mathrm{M}$ (testigo 1). $\mathrm{CA}=$ semillas embebidas y plantas asperjadas con $\mathrm{MgSO}_{4}$ al $0.03 \mathrm{M}$ (testigo 2). $\mathrm{F}=$ plantas inoculadas con $\mathrm{F}$. oxysporum. $\mathrm{M}=$ semillas embebidas con Methylobacterium. $\mathrm{MF}=$ plantas a partir de semillas embebidas con la bacteria e inoculadas con el hongo. MFA= semillas embebidas y plantas asperjadas con la bacteria e inoculadas con el hongo. 
Asimismo, hubo diferencias significativas en el diámetro de la planta (amplitud del follaje), medido a los 90 dds en los tratamientos inoculados con la bacteria, respecto al tratamiento $\mathrm{C}$ y al inoculado con $F$. oxysporum (Cuadro 2 y 3). Estos resultados fueron semejantes a los reportados en caña de azúcar, donde Methylobacterium sp. embebida en semilla y asperjada a la planta, registró diferencias estadísticas significativas en cuanto a la altura de la planta y el área foliar con respecto a $\mathrm{C}$, efectos que pudieran ser debidos a la producción o síntesis de fitohormonas (Madhaiyan et al., 2005; Ryu et al., 2006).

La producción promedio de jitomate en ambos ensayos, contrastó estadísticamente $(p \leq 0.05)$ entre los que involucraron a $M$. extorquens (M, MF y MFA) con los testigos (C y CA) y el tratamiento $F$, inoculado con $F$. oxysporum (Cuadro 4), lo que pudiera indicar, que la bacteria presentó una relación simbiótica, debido a que puede asociarse con las plantas en hojas, tallo, raíz y meristemos (Abanda-Nkpwatt et al., 2006).

Cuadro 4. Producción, peso promedio del fruto y peso seco de plantas de jitomate en invernadero, con y $\sin$ M. extorquens (primer ensayo).

\begin{tabular}{cccc}
\hline Tratamientos & Producción $(\mathrm{g})$ & Peso promedio del fruto $(\mathrm{g})$ & Peso seco de la planta $(\mathrm{g})$ \\
\hline $\mathrm{C}^{\star}$ & $434 \mathrm{bc}^{*}$ & $75.7 \mathrm{a}$ & $48.5 \mathrm{~b}$ \\
$\mathrm{CA}$ & $333.7 \mathrm{~cd}$ & $72 \mathrm{a}$ & $51 \mathrm{~b}$ \\
$\mathrm{~F}$ & $182 \mathrm{~d}$ & $47.5 \mathrm{~b}$ & $47.2 \mathrm{~b}$ \\
$\mathrm{M}$ & $647 \mathrm{a}$ & $71.7 \mathrm{a}$ & $63.5 \mathrm{a}$ \\
MF & $550.5 \mathrm{ab}$ & $72.5 \mathrm{a}$ & $52.2 \mathrm{~b}$ \\
MFA & $594.2 \mathrm{a}$ & $70.7 \mathrm{a}$ & $52.5 \mathrm{~b}$ \\
\hline
\end{tabular}

*= valores con diferente letra dentro de cada columna, son estadísticamente diferentes, Tukey $(p \leq 0.05) ; \mathrm{C}^{\star}=$ semillas embebidas en $\mathrm{MgSO}_{4}$ al $0.03 \mathrm{M}$ (testigo 1); $\mathrm{CA}=$ semillas embebidas y plantas asperjadas con $\mathrm{MgSO}_{4}$ al $0.03 \mathrm{M}$ (testigo 2); $\mathrm{F}=$ plantas inoculadas con F. oxysporum; $\mathrm{M}=$ semillas embebidas con Methylobacterium; $\mathrm{MF}=$ plantas a partir de semillas embebidas con la bacteria e inoculadas con el hongo: MFA= semillas embebidas y plantas asperjadas con la bacteria e inoculadas con el hongo.

Permitiendo el desarrollo de la planta de jitomate aun en condiciones de estrés por la presencia del patógeno (Trotsenko et al., 2001). Cabe señalar, que bajo condiciones 'in vitro', varias especies de Methylobacterium, han restringido el desarrollo de F. oxysporum en medio de cultivo papa dextrosa agar (Savitha et al., 2015), lo cual ha ocurrido también con M. extorquens (Poorniammal, 2009).

Con respecto al peso seco de la planta y de la raíz, solamente hubo diferencias significativas entre las plantas tratadas con $M$. extorquens por imbibición de las semillas (M) con el resto de los tratamientos (Cuadro 5), donde al parecer influyó mayormente la presencia del hongo, al cual se le atribuye la necrosis de la raíz y el marchitamiento vascular (Tello y Lacasa, 1988; Fernández et al., 2007), lo que implicaría un menor desarrollo y en consecuencia una disminución estadística en el peso seco del tratamiento $\mathrm{F}$ y en este caso también en el peso promedio del fruto (Cuadro 4 y 5). 
Cuadro 5. Producción, peso seco de la planta y de la raíz de jitomate en invernadero, con y sin M. extorquens (segundo ensayo).

\begin{tabular}{lccc}
\hline \multicolumn{1}{c}{ Tratamientos } & Producción $(\mathrm{g})$ & Peso seco de la planta $(\mathrm{g})$ & Peso seco de la raíz $(\mathrm{g})$ \\
\hline $\mathrm{C}^{\star}$ & $931.2 \mathrm{c}^{*}$ & $53 \mathrm{cb}$ & $16 \mathrm{cb}$ \\
$\mathrm{CA}$ & $953.5 \mathrm{c}$ & $60.2 \mathrm{~b}$ & $14.5 \mathrm{cb}$ \\
$\mathrm{F}$ & $807.5 \mathrm{~d}$ & $40 \mathrm{c}$ & $12.2 \mathrm{c}$ \\
$\mathrm{M}$ & $1248 \mathrm{a}$ & $75.5 \mathrm{a}$ & $31 \mathrm{a}$ \\
$\mathrm{MF}$ & $1067.5 \mathrm{~b}$ & $60.5 \mathrm{~b}$ & $20.7 \mathrm{~b}$ \\
MFA & $1068.7 \mathrm{~b}$ & $59.7 \mathrm{~b}$ & $19 \mathrm{cb}$ \\
\hline
\end{tabular}

$*=$ valores con diferente letra dentro de cada columna, son estadísticamente diferentes, Tukey $(p \leq 0.05)$; $\mathrm{C}^{\star}=$ semillas embebidas en $\mathrm{MgSO}_{4}$ al $0.03 \mathrm{M}$ (testigo 1); $\mathrm{CA}=$ semillas embebidas y plantas asperjadas con $\mathrm{MgSO}_{4}$ al $0.03 \mathrm{M}$ (testigo 2); $\mathrm{F}=$ plantas inoculadas con $F$. oxysporum. $\mathrm{M}=$ semillas embebidas con Methylobacterium. $\mathrm{MF}=$ plantas a partir de semillas embebidas con la bacteria e inoculadas con el hongo. MFA= semillas embebidas y plantas asperjadas con la bacteria e inoculadas con el hongo.

\section{Expresión de genes relacionados con la defensa de plantas de jitomate}

Los genes que codifican para el grupo enzimático fenilalanina amonio liasa (PAL), proteínas (PR6), superóxido dismutasa (SOD) y lipoxigenasa (LOX), no se expresaron significativamente en las plántulas tratadas $22 \mathrm{dds}$, con M. extorquens. Aun cuando PR-6 y PAL se les conoce como marcadores relacionados con la señal de defensa mediada por ácido salicílico, en el caso de PAL (Figura 1) no se expresa tanto como lo hace PR-6 justo a las $24 \mathrm{~h}$ (Figura 2) lo que pudiera resultar de la vía por la que se expresa, debido a que la PAL deriva de una secuencia más larga que la de PR-6.

Respecto a SOD se reprime parcialmente durante la fase de reconocimiento y después se dispara a las $72 \mathrm{~h}$ (Figura 3) con tendencia a reprimirse nuevamente después de ese tiempo, lo cual hace evidente que esas no son las vías por las cuales se da la inducción de resistencia en plantas inoculadas con M. extorquens. LOX no se expresó en ninguna de las pruebas, por lo que no se pudo obtener la intensidad en el gel de la imagen correspondiente.

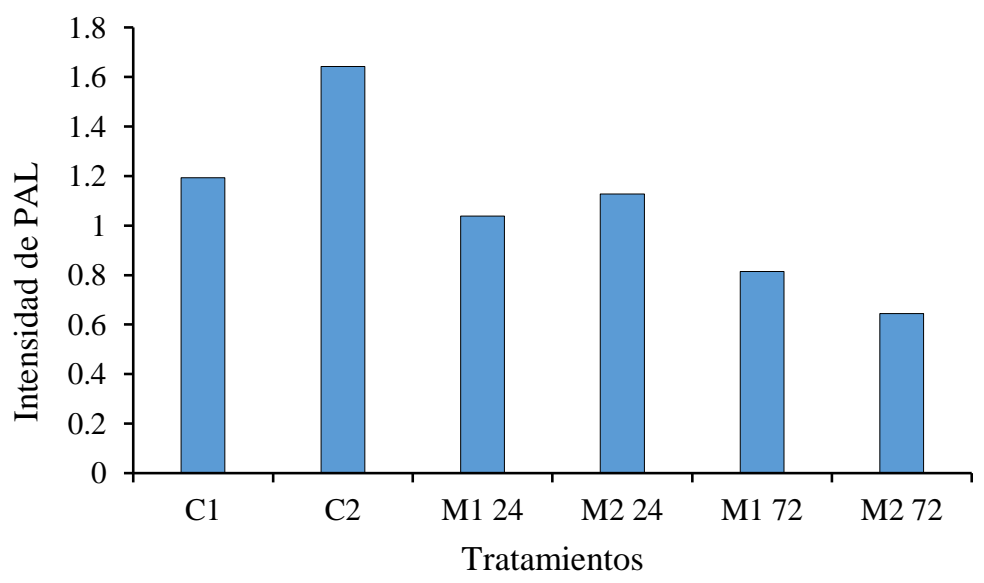

Figura 1. Intensidad del gen PAL en tratamientos con M. extorquens (M1 y M2 a 24 y 72 h) y sin la bacteria (C1 y C2 a 0 h), con una $n=3$ y un $\alpha 0.05$. 


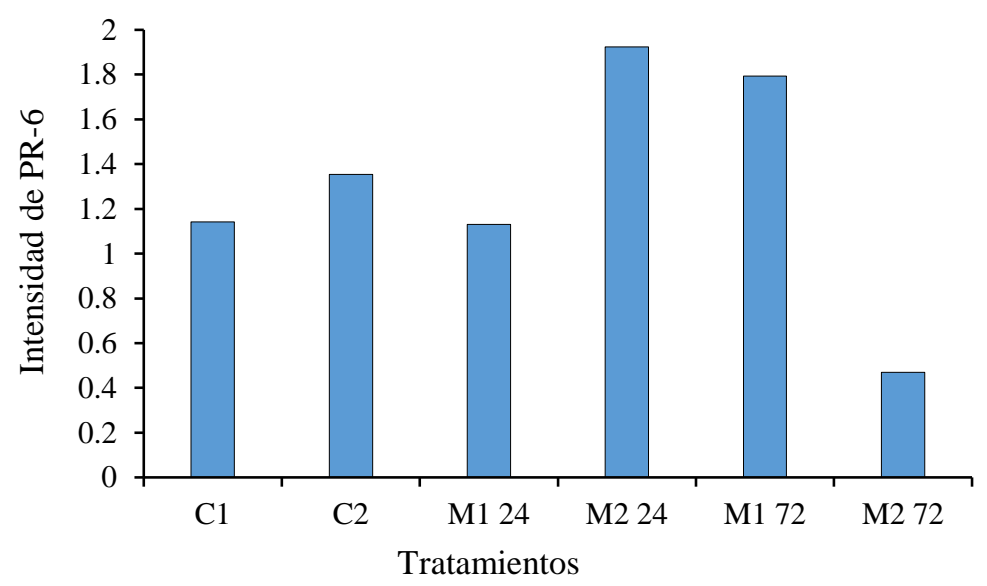

Figura 2. Intensidad del gen PR-6 en tratamientos con M. extorquens (M1 y M2 a 24 y 72 h) y sin la bacteria (C1 y C2 a 0 h), con una n= 3 y un $\alpha 0.05$.

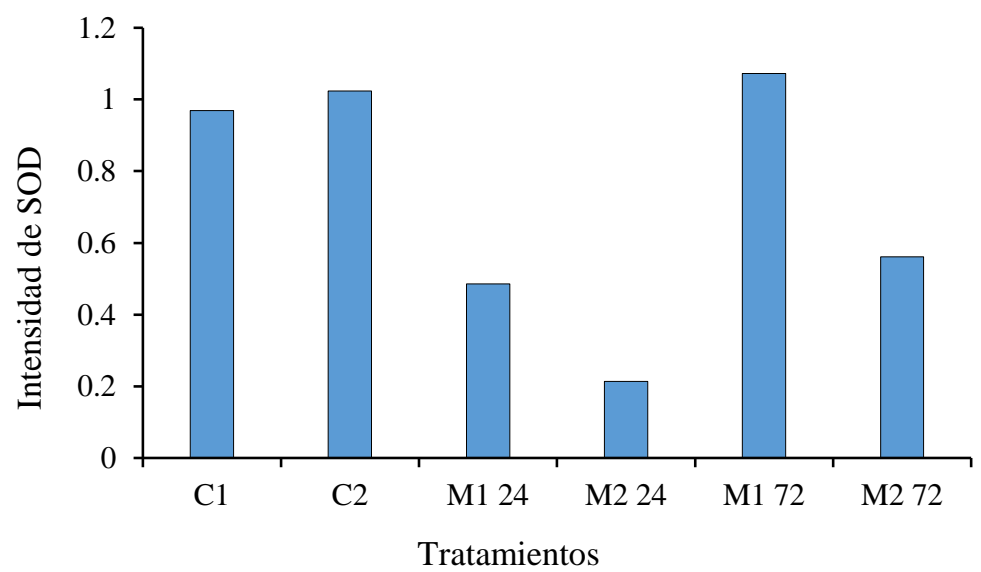

Figura 3. Intensidad del gen SOD en tratamientos con M. extorquens (M1 y M2 a 24 y 72 h) y $\sin$ la bacteria (C1 y C2 a 0 h), con una $n=3$ y un $\alpha 0.05$.

Es probable que no se haya incrementado la actividad enzimática relacionadacon los mecanismos de defensa, debido que, en las evaluaciones realizadas, no se retó a las plantas con el fitopatógeno en estudio, como sucedió en el caso de genotipos de trigo, donde se observó incremento en la actividad de PAL, la cual fue superior en los genotipos resistentes (HD 29 y DWL 5023) durante la infección del patógeno Neovossia indica (Gogoi et al., 2000) o la importancia que tiene la enzima LOX.

En la interacción tomate-Alternaria solani, donde la intensidad de las bandas obtenidas con LOX fueron mayores en variedades resistentes que en susceptibles, proteína que puede estar involucrada con los mecanismos de defensa en esa interacción (Solórzano et al., 2006). Sin embargo, se ha encontrado también que la inoculación de Metylobacterium sp., ha reducido el efecto de Rhizoctonia solani en plantas de arroz, incrementado la producción de proteínas relacionadas con la patogénesis (PR) y la producción de compuestos fenólicos en la planta. 
Un gran número de enzimas, incluyendo peroxidasa (PO), PAL, LOX, $\beta$-1,3-glucanasa y quitinasa se han asociado con la resistencia sistémica, aunque el aumento de la actividad y la acumulación de estas enzimas dependen principalmente del agente inductor, así como del genotipo de la planta, el estado fisiológico y el patógeno (Madhaiyan et al., 2004). Otro caso similar fue señalado en maní inoculado con Methylobacterium sp., donde se indujo protección contra Aspergillus niger y además mejoró significativamente la germinación y el vigor de las plántulas, aumentando también las proteínas PR y fenoles en comparación con los controles, y por lo tanto la inducción de las barreras físicas y químicas causadas por el aumento de actividades enzimáticas asociadas (Madhaiyan et al., 2006).

\section{Conclusiones}

La imbibición de semillas de jitomate variedad SUN 7705, en solución de $\mathrm{MgSO}_{4}$, inoculada con Methylobacterium extorquens a una concentración de $10^{9} \mathrm{UFC} \mathrm{mL}^{-1}$, promovió la longitud de la raíz de plántulas de jitomate y a la vez, el crecimiento y desarrollo del vegetal, reflejado en mayor peso seco de plantas y de raíces, así como en su rendimiento. No se incrementó la actividad enzimática relacionada con los mecanismos de defensa, debido probablemente a que, en las pruebas de expresión de genes de resistencia, faltó retar a la planta con el patógeno, por lo que se recomienda involucrarlo para que pueda provocar algún tipo de estrés y analizar también un mayor número de enzimas.

\section{Literatura citada}

Abanda-Nkpwatt, D. M. 2006. Molecular interaction between Methylobacterium extorquens and seedlings: growth promotion, methanol consumption, and localization of the methanol emission site. J. Exp. Bot. 57(15):4025-4032.

Ascencio-Alvarez, A.; López-Benítez, A.; Borrego-Escalante, F. y Rodríguez-Herrera, S. A. 2008. Marchitez vascular del tomate: I. Presencia de razas de Fusarium oxysporum f. sp. lycopersici (Sacc.) Snyder y Hansen en Culiacán, Sinaloa, México. Rev. Mex. Fitopatol. 26(2):114-120.

Carrillo-Fasio, J. A.; Montoya-Rodriguez, T. J.; Jarcia-Estrada, R. S.; Cruz-Ortega, J. E.; MarquezZequera, I. y Sañudo-Barajas, A. J. 2003. Razas de Fusarium oxysporum f. sp. lycopersici Snyder y Hansen, en Tomate (Lycopersicum esculentum Mill.) en el Vallle de Culiacán Sinaloa, México. Rev. Mex. Fitopatol. 21(2):123-127.

Corpe, W. A. 1985. A method for detecting methylotrophic bacteria on solid surfaces. J. Microbiol. Methods. 3(3-4):215-221.

Corpe, W. A. and Rheem, S. 1989. Ecology of the methylotrophic bacteria on living leaf surfaces. FEMS Microbiol. Ecol. 62(4):243-249.

Fernández, H. E.; Acosta, R. M.; Ponce, G. F. y Pinto, V. M. 2007. Manejo biológico de Phytophthora capsici Leo., Fusarium oxysporum schlechtend.:FR y Rhizoctonia solani Kuhn en jitomate (Lycopersicum esculentum Mill.). Rev. Mex. Fitopatol. 25(1):35-42.

Gogoi, R.; Singh, D. V. and Srivastava, K. D. 2000. Changing behavior of defense related enzymes in wheat during infection of Neovossia indica. Indian Phytophatol. 53(2):153-156.

Loredo-Osti, C.; López-Reyes, L. y Espinosa-Victoria, D. 2004. Bacterias promotoras de crecimiento vegetal asociadas con gramineas. Terra Latinoam. 22(2):225-239. 
Madhaiyan, M.; Poonguzhali, S.; Senthilkumar, M.; Seshadri, S.; Chung, H.; Jang, J.; Sundaram, S. and Sa, T. 2004. Growth promotion and induction of systemic resistance in rice cultivar Co-47 (Oryza savita L.) by Methylobacterium spp. Botanical Bulletin of Academia Sinica. 45(4):315-324.

Madhaiyan, M.; Poonguzhali, S.; Lee, H. S.; Hari, K.; Sundaram, S. P. and Sa, T. M. 2005. Pinkpigmented facultative methylotrophic bacteria accelerate germination, growth and yield of sugarcane clone Co86032 (Saccharum officinarum L.). Biol. Fertily Soils. 41(5):350-358.

Madhaiyan, M. S.; Suresh, R. B. V.; Anandham, R.; Senthilkumar, M.; Poonguzhali, S.; Sundaram, S. P. and Sa, T. 2006. Plant growth-promoting Methylobacterium Induceces defense responses in groundnut (Arachis hypogaea L.) compared with rod pathogens. Current Microbiol. 53(4):270-276.

Nelson, P. E.; Toussoun, T. A. and Marasas, W. F. O. 1983. Fusarium species: an illustrated manual for identification. The Pennsylvania State University press. 193 p.

Nóbrega-Dourado, M.; Camargo-Neves, A.; Souza-Santos, D. and Luiz-Araújo, W. 2015. Biotechnological and agronomic potential of endophytic pink-pigmented methylotrophic Methylobacterium spp. BioMed Res. Inter. 1-19 pp.

Poorniammal, R.; Sundaram, S. P. and Kumutha, K. 2009. In vitro biocontrol activity of Methylobacterium extorquens against fungal. Inter. J. Plant Protec. 2(1):59-62.

Ryu, J.; Munusamy, M.; Selvaraj, P.; Woojong, Y.; Pandiyan, I.; Kyounga, K.; Rangasamy, A.; Jongchul, Y.; Kyehoom, K. and Tomgmin, S. 2006. Plant growth substances produced by Methylobacterium spp. and their effect on tomato (Lycopersicom esculentum L.) and red pepper (Capsicum annuum L.) growth. J. Microbiol. Biotechnol. 16(10):1622-1628.

Savitha, P.; Sreenivasa, M. N. and Nirmalnath, J. P. 2015. In vitro screening for biocontrol activity of pink pigmented facultative methylotrophs against phytopathogens. Karnataka J. Agric. Sci. 28(2):286-287.

Solórzano, E.; Fernández, A.; León, O. y Peteira, B. 2006. Evaluación de indicadores bioquímicos en variedades de tomate resistentes al tizón temprano. Rev. Protección Veg. 21(2):101-108.

Sy, A.; Timmers, A. C.; Knief, C. and Vorholt, J. A. 2005. Methylotrophic metabolism is advantageous for Methylobacterium extorquens during colonization of Medicago truncatula under competitive conditions. Appl. Environ. Microbiol. 71(11):7245-7252.

Tello, J. C. y Lacasa, A. 1988. La podredumbre del cuello y de las raíces, causada por Fusarium oxysporum f.sp. radicis-lycopersici, nueva enfermedad en los cultivos de tomate (Lycopersicum esculentum Mill.) españoles. Boletín de Sanidad Vegetal. Plagas. 14(2):307-312.

Trotsenko, Y. A.; Ivanova, E. G. and Doronina, N. V. 2001. Aerobic methylotrophic bacteria as Phytosymbionts. Microbiology. 70(6):623-632.

Vargas, O. J. A. y Martínez, D. M. A. 2004. Un modelo econométrico del mercado del jitomate (Lycopersicum esculentum Mill.) en México, 1970-1994. Com. Socioec. Estadística e Informática. 8(2):115-133.

Weisburg, W. G.; Barns, S. M.; Pelletier, D. A. and Lane, D. J. 1991. 16S ribosomal DNA amplification for phylogenetic study. J. Bacteriol. 173(2):697-703. 